\title{
A DISASTER RELIEF INVENTORY MODEL BASED ON TRANSSHIPMENT
}

\author{
Pedro Reyes \\ Baylor Univeristy, United States \\ E-mail: Pedro_Reyes@baylor.edu \\ Jianghong Man \\ Shandong University, China \\ E-mail:manjh@sdu.edu.cn \\ Patrick Jaska \\ University of Mary Hardin-Baylor, United States \\ E-mail: pjaska@umhb.edu \\ Submission: 25/06/2013 \\ Accept: 30/07/2013
}

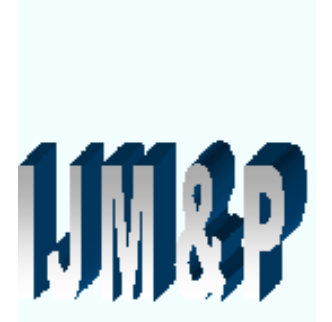

\section{ABSTRACT}

This research study is an effort to shed light on how transshipment may help improve the management of inventory in a disaster relief system. System dynamics simulation was used to compare inventory control and costs in a humanitarian supply chain without transshipment vs. one with transshipment. A framework for this approach is given along with the results of simulations on a system consisting of two warehouses where transshipment is allowed compared to the alternative where transshipment is not allowed. The preliminary results of this study indicate that transshipment can reduce costs and improve service to disaster victims based on inventory levels maintained in the warehouses. In some cases, transshipment may be more expensive, but this assumes the cost of replenishing inventory as a result of emergency purchase costs.

Keywords: systems dynamics, transshipment, disaster relief, humanitarian supply chains 
INDEPENDENT JOURNAL OF MANAGEMENT \& PRODUCTION (IJM\&P)

http://www.ijmp.jor.br

V. 4, n. 2, July - September 2013.

ISSN: 2236-269X

DOI: 10.14807/ijmp.v4i2.105

\section{INTRODUCTION}

Most disasters especially natural disasters cannot be predicted with accuracy beforehand, so it is hard to forecast the demand of post disaster supply, which is very essential for the recovery of the affected disaster areas. Uncertainties of the disasters themselves such as location, timing, degree of severity, and lack of financial and personal resources make it very difficult to match the demands caused by the disaster to the supply needed in a timely manner for disaster relief activities. That is, for the disaster relief supply chain, purchase planning cannot be made before the disaster happens, but must be fulfilled immediately after it happens. This is due to transportation difficulties and the absence of resources to supply disaster victims with needed medical and survival needs.

Storage of enough resources in strategic locations before a disaster with the use of transshipment can help to get supplies delivered to the right place after disaster. Humanitarian supplies such as food, clothing, personnel and medicine delivered to the affected areas after a disaster require a massive coordination effort. Disaster supply chain efforts are hampered by coordination difficulties, which may lead to resource scarcity or oversupply. Organizing relief inventories around the world with the right amount of supplies to the right place at the right time is important for the survival of victims of disaster. Many successful inventory models for commercial supply chains exist, but commercial supply chains are designed to reduce costs and raise customer-service levels, the supply chain for disaster relief requires a different model.

In this paper, we will focus on the inventory policies for both pre-disaster and post-disaster relief supply management. We will assume that the lead time of purchase is longer than transshipment from local warehouses, native warehouses and even global warehouses. Transshipment will be employed to determine how and where to store before a disaster and how and where to transship after a disaster. In the next section, we will review current literature based on the actions taken before and after disasters. In section 3, we will give a theoretic framework of the current relief supply decision system. We will discuss the sub system of the relief supply chain called the emergency transshipment system in section 4 . We will simulate the emergency supply chain with analysis in section 5 . Conclusions and recommendations for future research will follow in section 6 . 
INDEPENDENT JOURNAL OF MANAGEMENT \& PRODUCTION (IJM\&P)

http://www.ijmp.jor.br

v. 4, n. 2, July - September 2013.

ISSN: 2236-269X

DOI: 10.14807/ijmp.v4i2.105

\section{LITERATURE REVIEW}

\subsection{Humanitarian relief chain}

An emergency relief chain may include many flows, many actors. We will use Yang, et al. (2011) method to describe the current different emergency relief chains. They described eleven scenarios of commercial supply chains, such as electronic point of sales, vendor managed inventory, e-shopping, emergency transshipments, and so on in flow charts. Simulation was used based on Taguchi's methodology and multiple criteria decision-making methods to show that due to information sharing strategies, e-shopping has the most robust performance in uncertain business environments. In this paper, we will extend their work and discuss current literature on emergency supply chains. Pre-production emergency supply, post-production emergency supply, and post-transshipment emergency supply will be examined. The main information flows and material flows of each pattern are given in Figure.1.
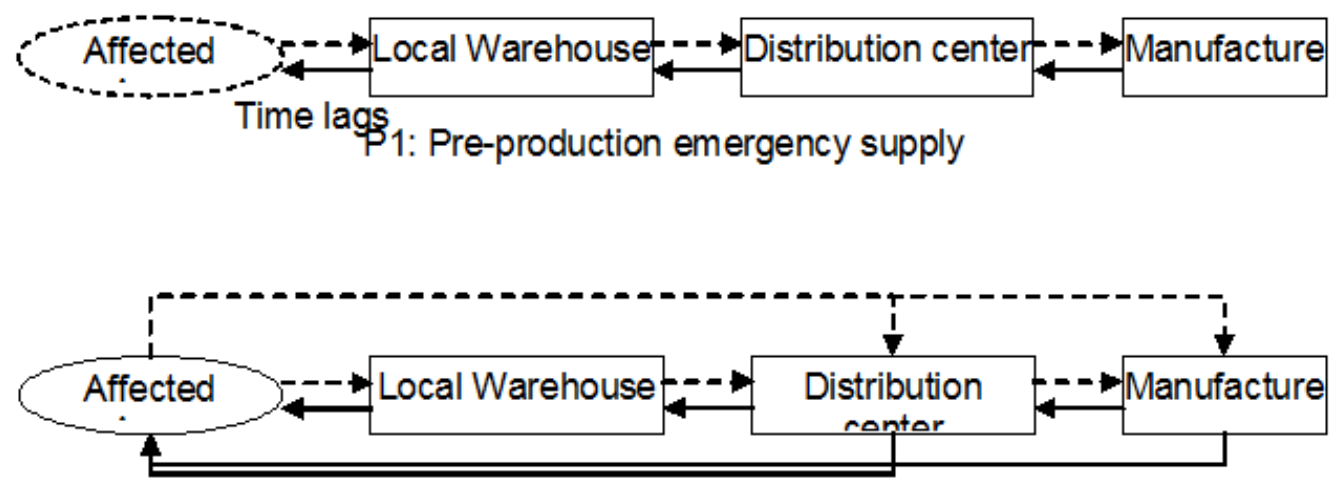

P2: Post-production emergency supply

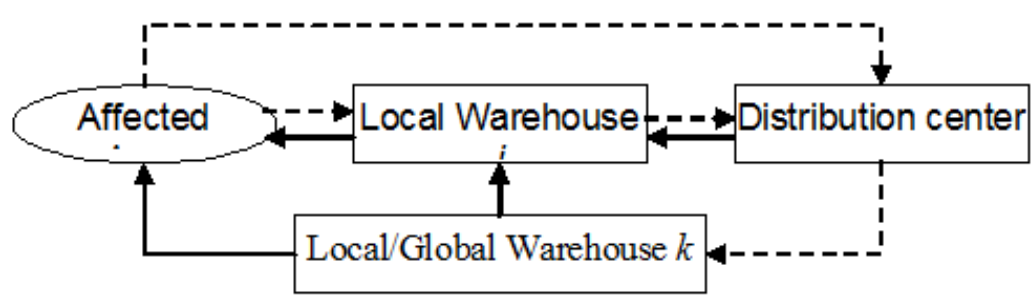

P3: Post-transshipment emergency

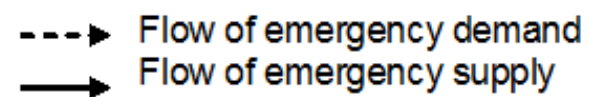

Fig 1. Three Basic Emergency supply patterns 
There are many actors in an emergency supply chain, such as international relief organizations, local relief organizations, local governments, donors, private sector companies and militaries. They were regarded as distributers or warehouses in Figure 1. Considering the uncertainties of changing demand, delivery lead time and transportation time, emergency relief chains are different from commercial supply chains. Government response can play an important role in the emergency relief chain, especially in the pre-disaster planning phase. Oloruntobsa (2010) proved this after analysis of the emergency relief chain for a 2005 cyclone (Cyclone Larry) in Australia. This is an example of the pre-production emergency supply, shown as P1 in Figure 1.

However, governments may not have the resources to provide disaster victims the needed supplies and services. So they can contract with the private sector to supply these goods and services. Since the private sector usually responds only in situations where profit is the motivating factor, it is up to the public sector to respond when the profit cannot be measured in monetary terms, but in lives saved. Egan (2010) illustrates how a hybrid system including the private, public, nonprofit, and local military can respond in a manner dependent on the capacity of each supporting entity. In Egan's model, coordination of the pre-disaster plan and the sharing information among support entities and individual aid workers is necessary to coordinate all four entities into a more focused system to avoid redundancies and contribute to a unified response effort. These relations can be described as postproduction emergency supply, shown as P2 in Figure 1, where the flow of emergency demand is ordered and given by government.

For the other actors besides government, Balcik, et al. (2010) gave some representative coordination procedures used by different entities in the humanitarian supply chain preceding and throughout the emergency. They divided supply flows into pre-disaster flow and post-disaster flow. For a pre-disaster flow emergency supplies and materials are purchased from local or global suppliers and stored in distribution centers before an anticipated disaster, while for a post-disaster flow emergency supplies and materials are distributed from distribution centers to various local distribution points after a disaster. These relations can be described as posttransshipment emergency supply, shown as P3 in Figure 1. Also, Balcik et al. (2010) examined the benefits, costs, required resources, and difficulties associated with the 
coordination procedures of commercial supply chains to show that some of the representative coordination procedures are applicable for relief chain coordination. For example, a third-party warehouse in the private sector is applicable to disaster relief because of low NGO technological requirements and medium operational risk costs. But the implementation related to inventory policy was not given. We will give some resolutions to this problem later in this paper.

\subsection{Disaster relief inventory and transshipment}

Lodree and Taskin (2009) formulated an inventory control problem as an optimal stopping problem with Bayesian updates. The updates are based on hurricane predictions using a dynamic programming algorithm to solve the problem. They gave examples involving real hurricane wind speed data to illustrate the methodology. But like other inventory models for emergency, they focus on the decision of one warehouse and pay no attention to transshipment between other warehouses. In fact, transshipments between warehouses or distribution centers are very efficient for supply chains, especially for disaster relief supplies.

Traditionally, an inventory system has a hierarchical design, with transportation flows from manufacturers to distributors and from distributors to retailers. A flexible system also allows lateral transshipments between distributors. Members at the same level can amalgamate their inventories, allowing them to reduce inventory levels and therefore costs while still attaining adequate service levels (PATERSON et al., 2010). Transshipments are successfully used in ebusiness, and also considered in the return recycling systems for its ability to make supply chains as lean as possible.

Many works have been done to construct a network with transshipments. Reyes (2005) used the Shapley value concept from cooperative game theory as an approach to solve the transshipment problem. In order to avoid backordering or losing sales, Tang and Yan (2010) analyzed two typical cross-docking operations: Pre-C, the manufacturer is aware of demand quantities of each store and tags the products accordingly. Post- $C$, handovers the distribution groundwork to the crossdock, closer to customers. Pre-C has less operations cost at the cross-dock but a larger quantity of transshipment while Post- $C$ has a greater operations cost but a smaller quantity of transshipment. They gave a mathematical model to solve this dilemma and analyzed the balance between inventory holding, shortage and 
transshipment costs. In mathematical models, there are often assumptions. For example, in the transshipment model, we often assume that the total lead time is less than the system order cycle and transshipped units reach their destinations at the start of the last period of the order cycle. Or we will assume that the unfulfilled demand with in-house stock at a distribution center will be provided by lateral transshipments from other distribution centers when needed.

As shown earlier, there are many differences in the environment and characteristics of disaster relief inventories. For example, when planning for inventory location, besides the time and cost of transportation to the potential demand points, we must pay attention to political considerations. Furthermore, the inventory location and inventory accessibility must be known for monitoring or shipping when the need arises. Considerations of security, possible government corruption and other factors usually not considered in the management of inventories for enterprises need to be accounted for (WHYBARK, 2007). In this paper, we will expand transshipment to the disaster relief inventory policy.

\section{THEORETICAL FRAMEWORK}

The theoretical framework of the relief supply decision system is shown in Figure 2. There are four sub systems in the framework, called purchase, inventory, distribution, and information technology and knowledge discovery. In this paper, we assume that the lead time of transshipment between warehouses is always shorter than the total time of purchase lead time and order fulfill time from suppliers. Therefore, besides these four sub systems, we define a new system called emergency transshipment. And we will describe emergency transshipment based on system dynamics and then simulate the system. 


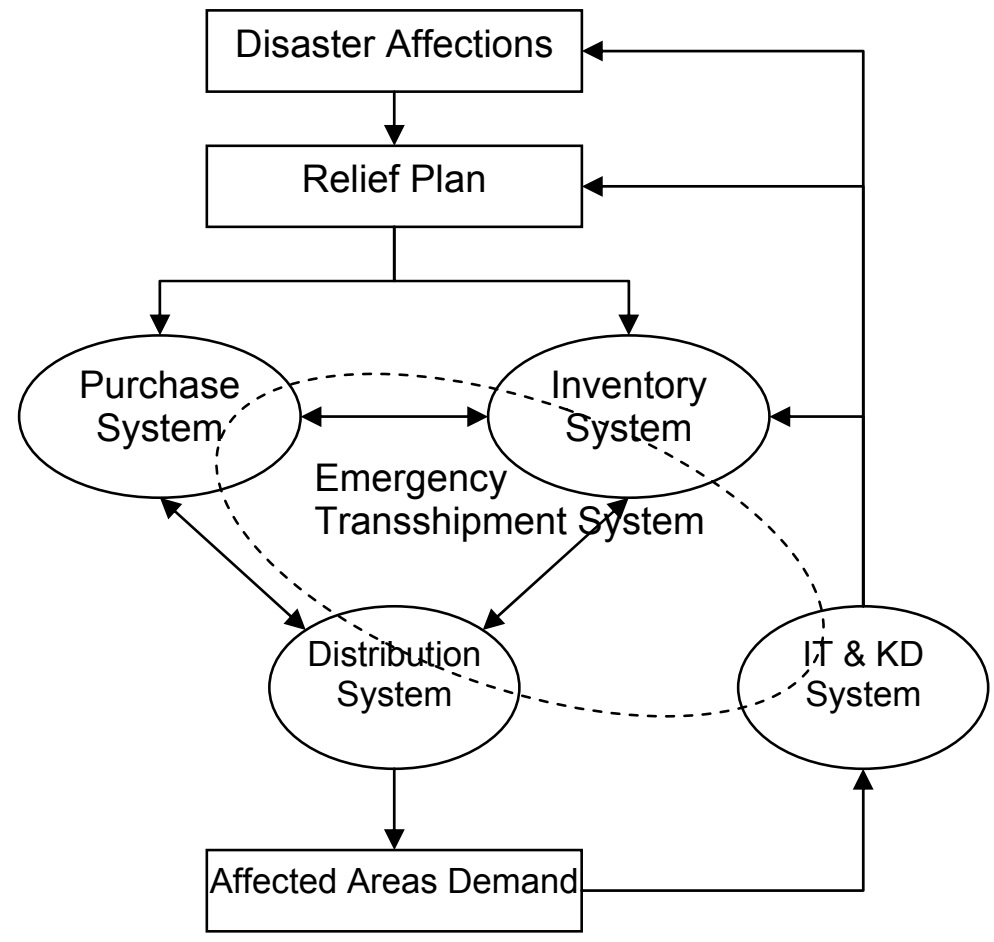

Fig.2. Framework of Relief Supply Decision System

\subsection{Information technology and knowledge discovery (IT \& KD) system}

Information sharing is very useful in solving the uncertainties along the commercial supply chains, companies use Internet standards internally and externally as well as other information technologies to improve their competitiveness and quality of customer service. For a relief supply decision system, information sharing and information management are rather important. With information technologies, such as GIS, we can identify the location and geographical information of affected areas. With information sharing technology, the information of the disaster can be easily transferred to other areas and departments via information technologies such as EDI and location tracking. As a result, the distribution centers, suppliers and even commercial supply chains can be ready to react as soon as possible. Moreover, after the disaster, even the affected area itself will be uncertain about the relief demands, such as rescue timeline, materials and personnel needs. Fortunately, based on local information and history knowledge data bases of similar disasters, the knowledge discovery method can help. We can identify the accuracy of relief demand, such as quality and quantity of materials and available transportation abilities. 
Using the information technology and knowledge discovery (IT \& KD) system, we can input affected area information and output reliable relief plans, such as how to get the relief supplies, by transshipment or purchasing, purchase natively or globally. If our relief plan is to purchase, then we go to purchase system, or else we go to the inventory system to judge if the storages in local warehouse are enough or if transshipments are necessary, and how to choose the suppliers? In order to meet the transshipment requirements and facilitate rapid shipping between warehouses, advanced information systems must be in place to allow actors to know what other actors have in stock.

\subsection{Purchase system}

The purchase system includes two sub systems called pre-purchase and emergency purchase. The operation characters of pre-purchase are the same as that of commercial purchase. But the pre-purchase relief demand is more difficult to predict than commercial demand. Moreover, the unfulfilled demand cannot be backfilled and the lost sale will lead to another disaster. In pre-purchase, we can use most of the purchase models of commercial supply chains, where some parameters and functions will need to be modified. We will focus on this topic in our lateral works. In this paper, we assume that the cost of pre-purchasing is higher due to the uncertainties of demand, hurriedness of lead time and poor transportation conditions. Of course, purchasing is necessary if all of the regional/local warehouses were seriously damaged after disaster.

Another important function of our purchase system in Figure 2 is emergency purchasing, which is always necessary when disaster happens and some of or even all of local inventories are seriously destroyed. Emergency purchase is totally different from pre-purchase, not only in its purchase time and purchase quantity, but also in the probable inaccessibility of demand points. The suppliers must be prepared to produce adequate materials for relief and ship them immediately anywhere at any time, which is impossible.

Before a disaster, warehouses must place their orders based on the prediction of relief demands and share their inventories with suppliers via information technologies. If a disaster happens, the purchase system can work out an emergency purchase plan if the output of IT \& KD system is to purchase and produce instead of using transshipment. 


\subsection{Inventory system}

In our model, the inventory system includes warehouse network redesign and storage planning. It manages the raw material and production of the purchase system and the finished production that can be transshipped to other areas. Mathematics models are necessary in this kind of system. Classic inventory models include mathematical models that take into account surplus, shortage and ordering costs and are used to determine inventory parameters such as the re-order level $(R O L)$ and re-order quantity (ROQ). However, the humanitarian relief model does not match the classic inventory model because of the low and unknown probability of the specific event, the uncertainty timing, and the difficulties in ascertaining risk levels and the potential severe consequences. Bonney and Jaber (2010) suggested that performance measures should encourage the positive aspects of holding inventory, such as providing flexibility, providing resources that allow things to be made, acting as a buffer, and satisfying demand immediately. In this work, we will not use traditional optimal inventory models.

In our model, we suppose that the frequency of disasters is not known but the maximum demand can be deduced based on the local disaster records and other similar cases via knowledge discovery technology. As a result, the inventory policy is to trace a constant which can minimize the total cost. Higher inventory will make relief easier, however too much inventory will lead to high purchase and inventory holding costs. But lower inventory can cause higher risk, if emergency purchasing is inefficient. Besides the time cost, inventory policies of relief materials are affected by many factors such as cost to produce, transport and store relief material. Various effects of these factors can be transferred mathematically into a parameter, regarded as cost in this work.

\subsection{Distribution system}

A distribution system includes transportation and delivery optimization before and after disaster. Transportation includes distributing materials from suppliers to store them in local warehouses before a disaster. Delivery means delivering relief supplies from local or global warehouses to the affected area after a disaster, just as order fulfillment in a commercial supply chain. Due to the differences between relief demand and commercial demand, distribution planning after a disaster is more 
INDEPENDENT JOURNAL OF MANAGEMENT \& PRODUCTION (IJM\&P)

http://www.ijmp.jor.br

v. 4, n. 2, July - September 2013.

ISSN: 2236-269X

DOI: 10.14807/ijmp.v4i2.105

important than that of before a disaster. Also, it is different from the efficient strategies in commercial distribution, such as cross-docking and direct shipment.

Because the warehouses must cooperate to fulfill the demand when an emergency occurs, we prefer a centralized distribution strategy. Centralized distribution can even lead to global optimization in commercial supply chains when a network is owned by a single entity or a centralized system that includes many organizations. In relief supply systems, besides cooperation among warehouses owned by one distribution center, distribution systems must cooperate with other systems. For example, a distribution system must cooperate with an inventory system to judge the optimal transport and storage quantities. Also, the time cost of distribution and delivery is very important to the decision of transshipment and purchase systems. Transportation optimization of a disaster relief plan is more complex than that of commercial logistics because of the possible absence of an information route condition and other resources. That is, a distribution system depends most on the IT \& KD system.

\subsection{Transshipment system}

In commercial inventory models based on transshipments, when a customer cannot be satisfied by stock on hand or via lateral transshipment, we can assume that the demand is backordered or a lost sale (Olsson, 2010). But in our emergency relief chain, if the demand of post-disaster cannot be satisfied by local storage or via lateral transshipment from native or global warehouses, we cannot assume backorder or lost sale, we must switch to purchase or produce. The failure of a transshipment system will be a disaster for a relief supply chain. Therefore, this sub system must cooperate well with other sub systems such as inventory, distribution, IT \& KD system, and even purchase systems. That is, the transshipment planning system is rather complex for the decision variables are outputs of other sub systems and at the same time the outputs of it will affect the decisions of other sub systems. Considering this kind of interaction, using a traditional mathematic model such as stochastic mixed integer program to describe this transshipment system and try to get the optimized policy is impossible. In the next section, we will use a system dynamics method to describe an emergency transshipment system and give a simulation in section 5 . 
INDEPENDENT JOURNAL OF MANAGEMENT \& PRODUCTION (IJM\&P)

http://www.ijmp.jor.br

v. 4, n. 2, July - September 2013.

ISSN: 2236-269X

DOI: 10.14807/ijmp.v4i2.105

\section{EMERGENCY TRANSSHIPMENT SYSTEM}

We will consider the emergency supply pattern with transshipment shown in Figure 1 as P3, where there is one distribution center and many local and global warehouses belonging to it. Before a disaster, goods are distributed from distributer centers to local and global warehouses, the costs include transportation, storage, etc. After a disaster, the demand can be satisfied first with the nearest undestroyed local warehouse. If the supplies are not enough, we can switch to other local warehouses or global warehouses. We will first design a single warehouse model and then describe the interaction between warehouses, which includes a transshipment system.

\subsection{Inventory structure for single warehouse with transshipment}

Assume there is one distribution center with many warehouses. Warehouses are denoted as inventory i, j, k... First, we will model one warehouse, inventory i. An inventory structure of single warehouse is given in Figure 3.

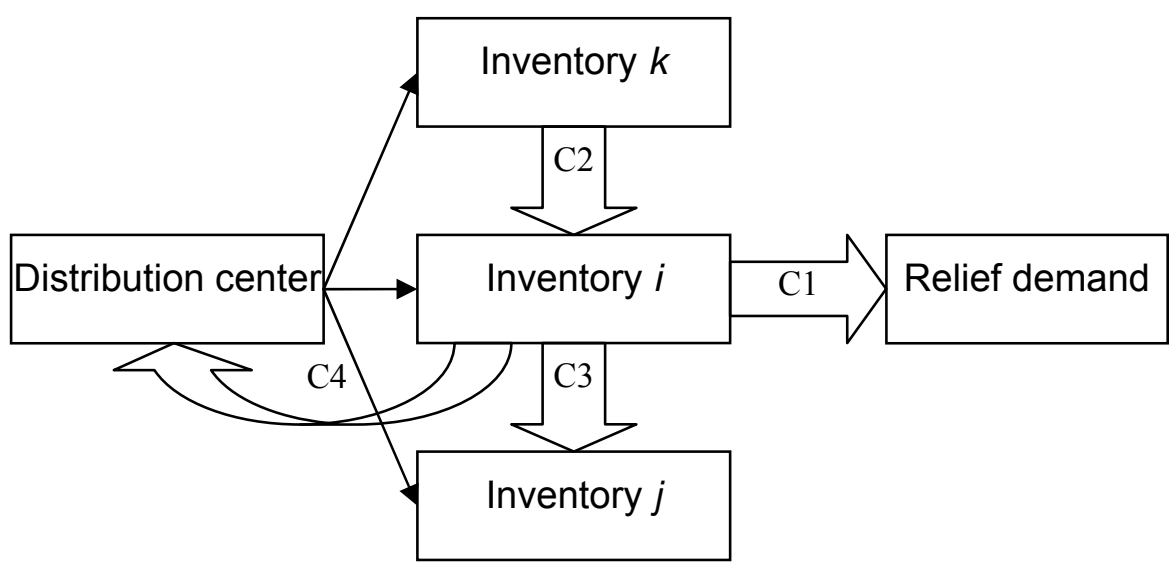

Fig 3. Inventory structure of single warehouse based on transshipment

In Figure 3, local inventory i has two resources, pre-purchase from distribution center and post-transshipment from local inventory k. In case of the uncertainty of relief demand, we must purchase goods and store them as inventories beforehand, we call this pre-purchase. The basic purchase policy is if the disaster happened and the local warehouse, inventory $i$ is not destroyed, the relief demands can be fulfilled by inventory $i$. The pre-purchase of inventory $i$ is based on the potential demand and prediction of damages. If the disaster happened and the local warehouse $i$ is 
destroyed, the relief demands must be fulfilled by transshipments. We assume that at least one warehouse will fulfill the relief demand, in our model marked as inventory k.

Of course, if the disaster does not happen locally, then inventory i can be used to fulfill the relief demand of other areas, such as inventory j shown in Figure 3, whose local inventory is totally destroyed. If no disasters happen before the expiration date of materials, we must redistribute them or dispose of them, which will lead to re-transport and other costs.

\subsection{Inventory policy for single warehouse with transshipment}

We use the following parameters:

$p_{i}=$ probability of region i being destroyed

$q_{i}=$ probability of inventory $\mathrm{i}$ being destroyed and inaccessible

$p_{t i}=$ probability of condition $\mathrm{t}$ of region $\mathrm{i}$, where $\mathrm{t}=1,2,3,4$

$x_{i}=$ inventory of region $\mathrm{i}$

$D_{i}=$ real demand of region $\mathrm{i}$

$c_{p i}=$ unit pre-purchase and storage cost of inventory $\mathrm{i}$

$c_{d i}=$ unit disposal cost of inventory $\mathrm{i}$

$c_{t k i}=$ unit transshipment cost from $\mathrm{k}$ to $\mathrm{i}$

$p_{1 i}=p_{i}\left(1-q_{i}\right)=$ real demand of region $\mathrm{i}$

Condition 1: Region i being destroyed and inventory $\mathrm{i}$ is accessible. Probability of this condition is

$$
p_{1 i}=p_{i}\left(1-q_{i}\right)
$$

Under this condition, there will be relief demand in region $i$ and this demand can be fulfilled by inventory $i$. The total cost of this condition is as follows:

$C_{1 i}=c_{p i} D_{i}+c_{d i}\left(x_{i}-D_{i}\right)$ 
If the real demand $D_{i}$ is less than inventory $x_{i}$, the storage not used must be redistributed to commercial supply chain or disposed of. In this paper, we call this disposal cost, which indeed varies for various goods and warehouses. But we will define disposal costs to include the cost of purchase, storage, retransmittal, and disposal.

Condition 2: Region $\mathrm{i}$ being destroyed and inventory $\mathrm{i}$ is inaccessible. Probability of this condition is

$$
p_{2 i}=p_{i} q_{i}
$$

Under this condition, there will be relief demand in region $i$ and this demand must be fulfilled by transshipment from other regions, inventory $k$. The total cost of this condition is

$$
c_{2 i}=c_{p i} X_{i}+c_{t k i} D_{i}
$$

Condition 3: Region i being safe but Region $\mathrm{j}$ being destroyed and inventory $\mathrm{j}$ is inaccessible. Probability of this condition is

$$
p_{3 i}=\left(1-p_{i}\right) p_{j} q_{j}
$$

Under this condition, there will be relief demand in region $\mathrm{j}$ and this demand can be fulfilled by inventory $\mathrm{i}$. The total cost of $\mathrm{i}$ is only the pre-purchase and storage cost ci, just the same as condition 1 . Of course there is transshipment cost from $i$ to $j$, but it belongs to inventory $\mathrm{j}$.

$c_{3 i}=c_{p i} D_{j}+c_{d i}\left(x_{i}-D_{j}\right)$

Condition 4: Region i being safe and other inventory $\mathrm{j}$ is accessible. Probability of this condition is

$$
p_{4 i}=\left(1-p_{i}\right)\left(1-p_{j} q_{j}\right)
$$

Under this condition, there will not be relief demand in any region. The storage must be redistributed to commercial supply chain or disposed. The total cost is:

$$
c_{4 i}=c_{d i} X_{i}
$$

Now comes the total cost of inventory $\mathrm{i}$ 
$c_{i}=\sum_{t=1}^{4} p_{t i} c_{t i}$

[1]

Notice that in equation [1], total cost depends on many variables: the possibility of disaster and possibility of warehouse corruption; unit cost of purchase, storage, disposal, transshipment, redistribution; inventory holdings and real disaster relief demand. It is impossible to get the optimal solution and minimize the cost. Furthermore, in relief supply management, we pay more attention to the fulfillment of demand. Therefore, we will simulate our model using system dynamics and discuss the sensitivity of the system.

\subsection{Inventory system design with transshipment}

In this section, we assume there are two warehouses located in different areas with different $p_{i}$, probability of being destroyed. Each of them is accessible to the other one. For example, if disaster happens in region $i$ and inventory $i$ is out of order, then the relief demand can be fulfilled by transshipment from inventory $\mathrm{j}$. Also, the transshipment of region $\mathrm{j}$ can be fulfilled by inventory i if necessary.

Causal loop diagram of transshipment is given in Figure 4.

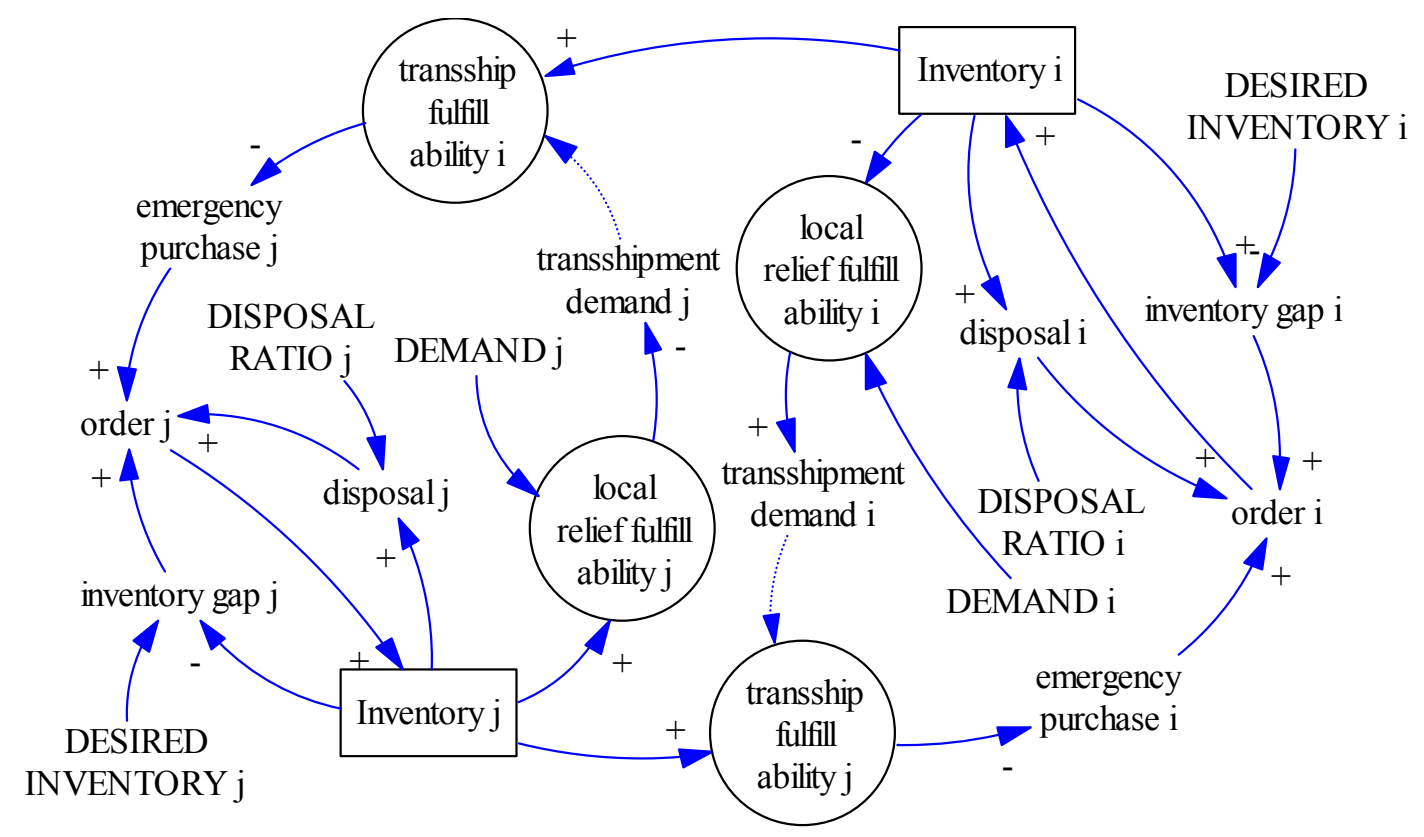

Figure 4: Causal loop diagram of transshipment

In Figure 4, besides the negative and positive loops of Inventory $i$ and Inventory j, the following loop is very important: 
INDEPENDENT JOURNAL OF MANAGEMENT \& PRODUCTION (IJM\&P)

http://www.ijmp.jor.br

v. 4, n. 2, July - September 2013.

ISSN: 2236-269X

DOI: 10.14807/ijmp.v4i2.105

Inventory $\mathrm{i} \rightarrow$ +transship fulfill ability $\mathrm{i} \rightarrow$-emergency purchase $\mathrm{j} \rightarrow+$ order $\mathrm{j} \rightarrow+$ Inventory $\mathrm{j} \rightarrow$ +transship fulfill ability $\mathrm{j} \rightarrow$-emergency purchase $\mathrm{i} \rightarrow+$ order $\mathrm{i} \rightarrow+$ +Inventory $\mathrm{i}$

This loop indicates that the Inventory $\mathrm{i}$ and Inventory $\mathrm{j}$ are connected with transshipment. Their inventory policy can be different due to transshipment. In the next section, we will prove this via simulation.

\section{SIMULATION AND ANALYSIS}

\subsection{Data and assumptions}

We will discuss three probabilities of disaster and three inventory policies in our simulation, called high, medium and low. Different probabilities of disaster are shown in Figure 5. In this example, inventory equals 100, 200, and 400.
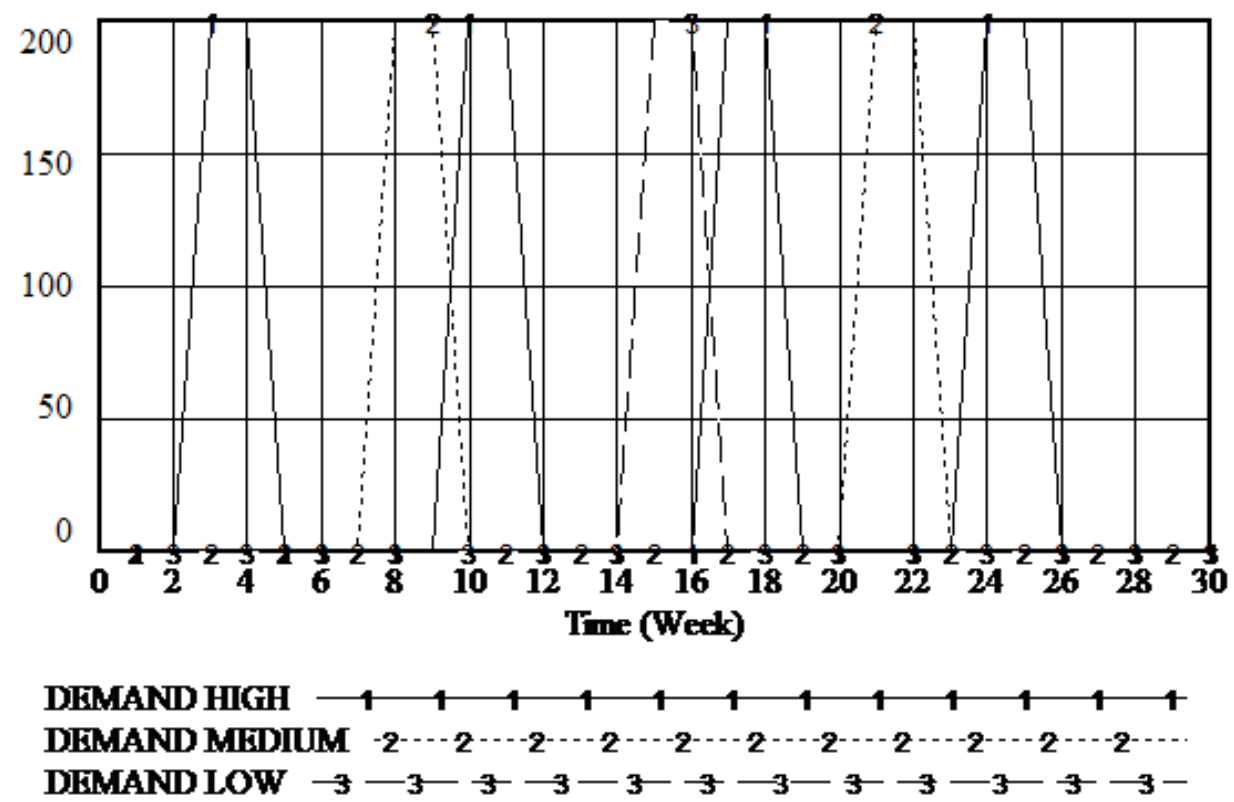

Figure 5. Different probability of relief demand

Now comes the stock and flow structure of Inventory i, shown in Figure 6. 
INDEPENDENT JOURNAL OF MANAGEMENT \& PRODUCTION (IJM\&P)

http://www.ijmp.jor.br

V. 4, n. 2, July - September 2013.

ISSN: 2236-269X

DOI: 10.14807/ijmp.v4i2.105

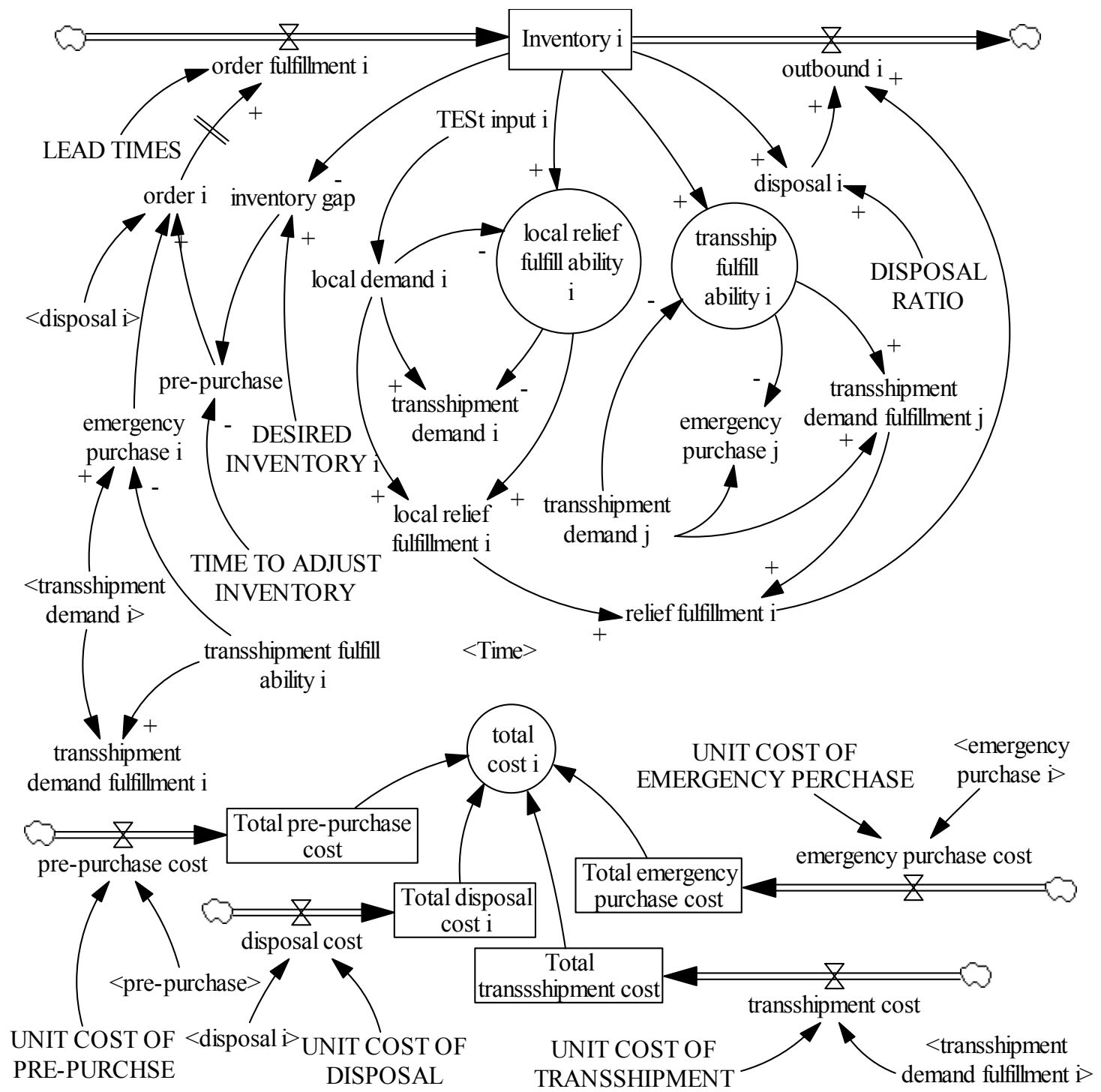

Figure 6: Stock and flow diagram of one relief warehouse

\subsection{Simulation without transshipment}

In order to simulate a single warehouse relief without transshipment, let:

Transshipment demand $\mathrm{j}=0$

This means inventory $\mathrm{i}$ is only used as local relief and cannot offer transshipment supply to j. In other words, there would be no C3 in Figure 3. Furthermore, we can also suppose there is no transshipment supply to inventory $\mathrm{i}$ by the following statement:

Emergency purchase $\mathrm{i}=$ transshipment demand $\mathrm{i}$

This equation means there would be no $\mathrm{C} 2$ in Figure 3. 
INDEPENDENT JOURNAL OF MANAGEMENT \& PRODUCTION (IJM\&P)

http://www.ijmp.jor.br

V. 4, n. 2, July - September 2013.

ISSN: 2236-269X

DOI: 10.14807/ijmp.v4i2.105

When demand is low, a different inventory policy can lead to a different total cost, shown in the left of Figure 7. For medium and high demand, the results are shown in the middle and right of Figure 7.

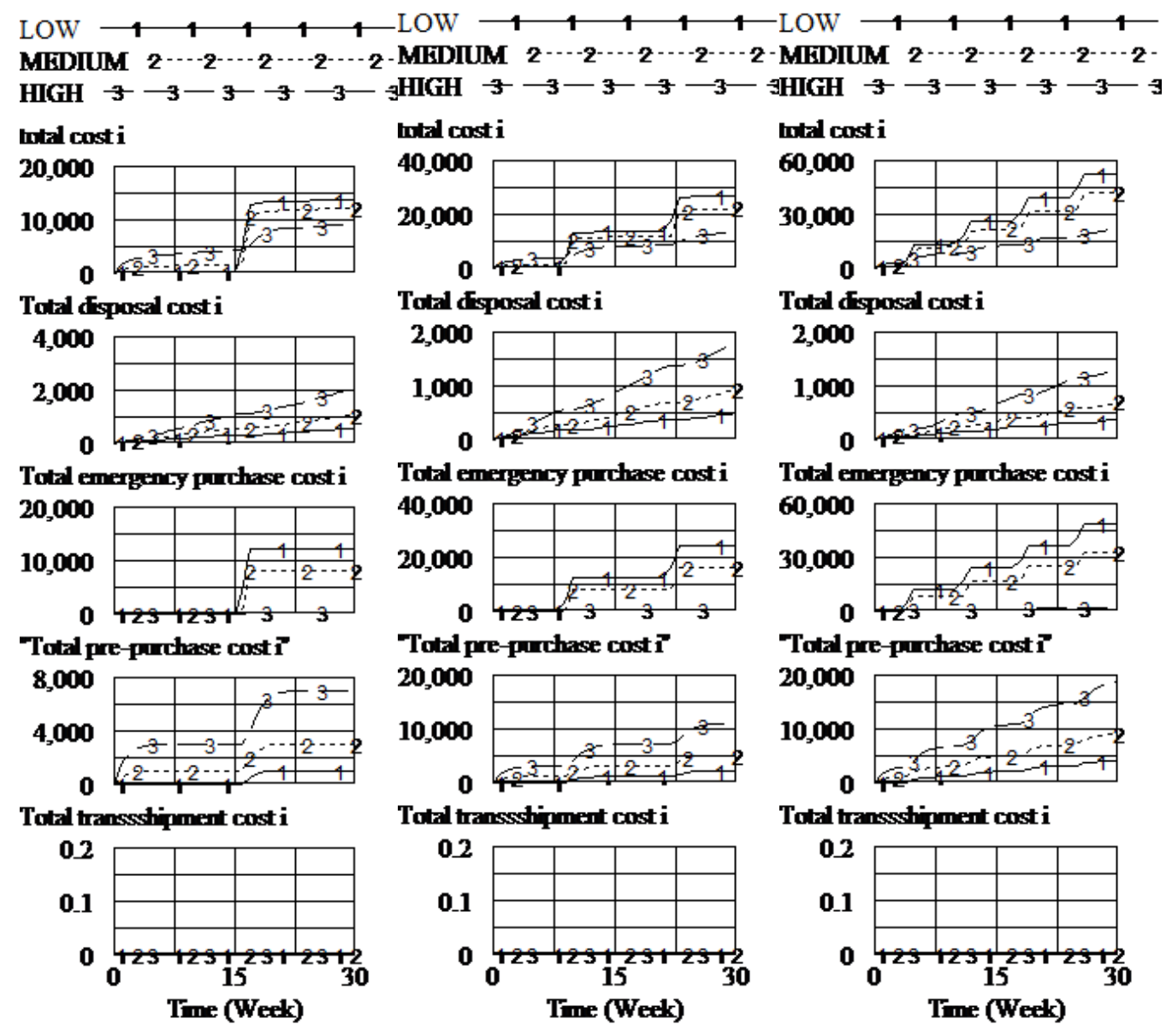

Figure 7: Cost of different inventory policy without transshipment

From Figure 7, we can see that if the relief demand is high, medium or low, the desired inventory should be high to avoid the high emergency purchase cost. At the same time, high desired inventory can lead to high disposal and redistribution costs. In fact, because of the uncertainty of disaster frequency and in order maintain efficiency of relief, we prefer to keep a high inventory which will lead to high costs and waste of recourses, especially when relief demand is low.

Notice the negative loop in the inventory system without transshipment:

Inventory $\mathrm{i} \rightarrow$ +local relief fulfill ability $\mathrm{i} \rightarrow$-transshipment demand $\mathrm{i} \rightarrow$ +emergency purchase $\mathrm{i} \rightarrow$ +order $\mathrm{i} \rightarrow$ +order fulfillment $\mathrm{i} \rightarrow+$ Inventory $\mathrm{i}$.

An ordinary, negative feedback mechanism can restrict the endless accumulation of inventory. But in this loop, like in the commercial supply chain, the 
INDEPENDENT JOURNAL OF MANAGEMENT \& PRODUCTION (IJM\&P)

http://www.ijmp.jor.br

V. 4, n. 2, July - September 2013.

ISSN: 2236-269X

DOI: 10.14807/ijmp.v4i2.105

unfulfilled local relief demand is directly pushed to emergency purchase, which has a lead time to fulfill. In disaster relief supply, the lead time may lead to a serious postdisaster. Therefore, transshipment is introduced to avoid both the cost and inefficiency of emergency purchase.

\subsection{Simulation with transshipment}

Based on different disaster frequencies, simulations are divided into nine groups, shown in Table 1.

Table 1 Different disaster frequency

\begin{tabular}{|l|l|l|}
\hline $\begin{array}{l}\text { Character of } \\
\text { Disaster }\end{array}$ & $\begin{array}{l}\text { Disaster frequency of } \\
\text { FLL }\end{array}$ & LOW \\
\hline FLM & LOW & LOW \\
\hline FLH & LOW & MEDIUM \\
\hline FML & MEDIUM & HIGH \\
\hline FMM & MEDIUM & LOW \\
\hline FMH & MEDIUM & MEDIUM \\
\hline FHL & HIGH & HIGH \\
\hline FHM & HIGH & LOW \\
\hline FHH & HIGH & MEDIUM \\
\hline
\end{tabular}

In every group, we simulate six inventory policies, shown in Table 2.

Table 2 Different inventory policy

\begin{tabular}{|l|l|l|}
\hline Inventory policy & Inventory $i$ & Inventory $j$ \\
\hline ILL & LOW & LOW \\
\hline IML & MEDIUM & LOW \\
\hline IMM & MEDIUM & MEDIUM \\
\hline IHL & HIGH & LOW \\
\hline IHM & HIGH & MEDIUM \\
\hline IHH & HIGH & HIGH \\
\hline
\end{tabular}


INDEPENDENT JOURNAL OF MANAGEMENT \& PRODUCTION (IJM\&P)

http://www.ijmp.jor.br

V. 4, n. 2, July - September 2013.

ISSN: 2236-269X

DOI: 10.14807/ijmp.v4i2.105

\subsection{Total cost of different inventory policies with transshipment}

Total cost of six inventory policies with nine disaster frequency conditions are given in Figure 8-Figure 16.
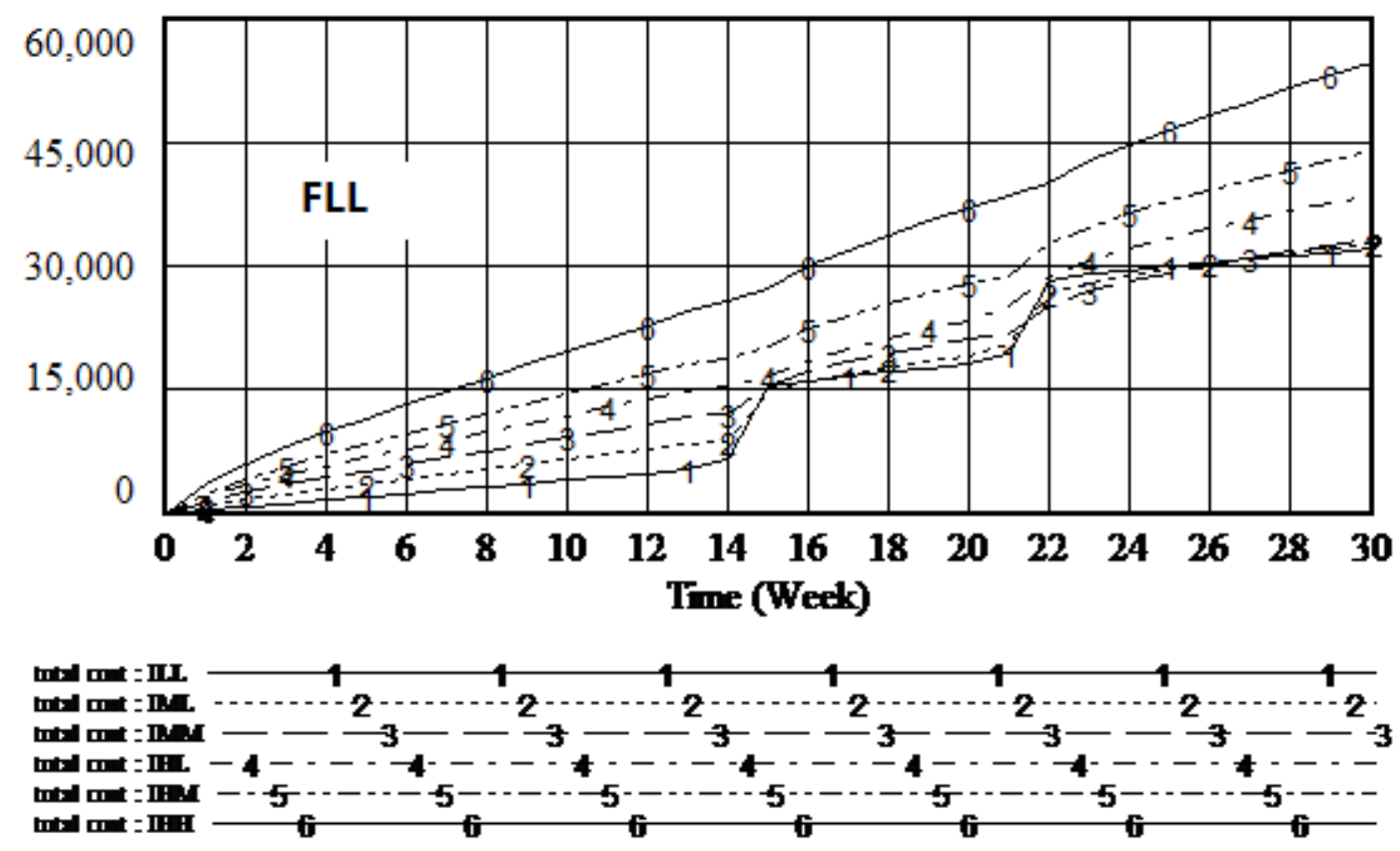

Figure 8: Total cost of different inventory policies with transshipment when disaster frequency is low \& low

In Figure 8, under condition FLL, where the disaster frequencies of $\mathrm{i}$ and $\mathrm{j}$ are all low, the total cost of inventory policy IHH is the highest, see line 6 in Figure 8 . The lowest total cost appears when inventory policies are ILL, IML, IMM, see line 1, 2, 3 in Figure 8. We can see that when both of the relief demands are low, the desired inventories of both inventory $i$ and inventory $j$ should not be high. This conclusion is different from that of 5.2 because transshipment is introduced to the system, demand of emergency purchase can be satisfied by transshipment. 

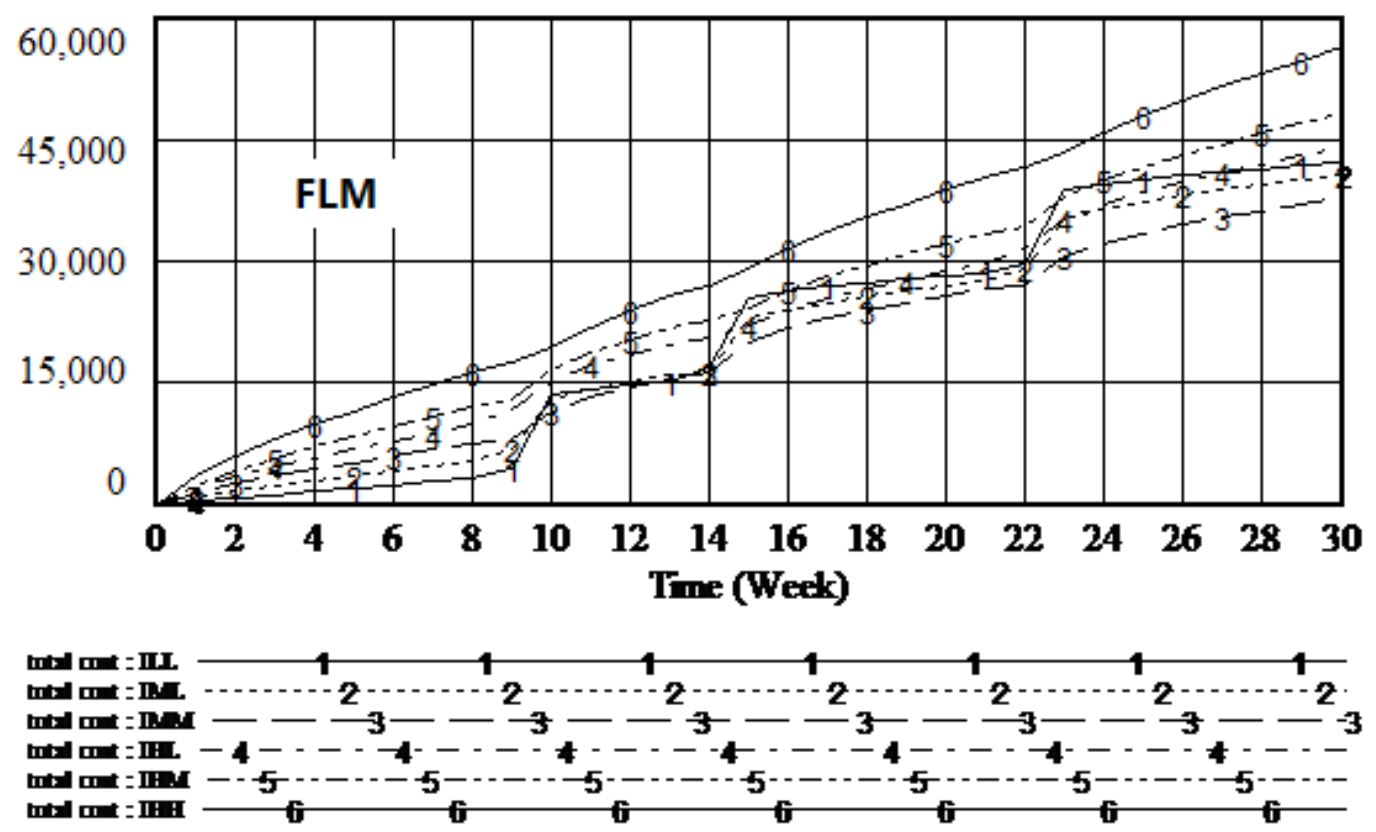

Figure 9: Total cost of different inventory policies with transshipment when disaster frequency is low \& medium

In Figure 9, under condition FLM, where the disaster frequency of $i$ is low and the disaster frequency of $\mathrm{j}$ is medium, the total cost of inventory policy $\mathrm{IHH}$ is also the highest, see line 6 in Figure 9. The lowest total cost appears when inventory policy is IMM, see line 3 in Fig 8. However, the total costs of inventory policies ILL and policy IML are higher than that of policy IMM. We can see that the best desired inventory occurs when both of them hold a medium inventory.

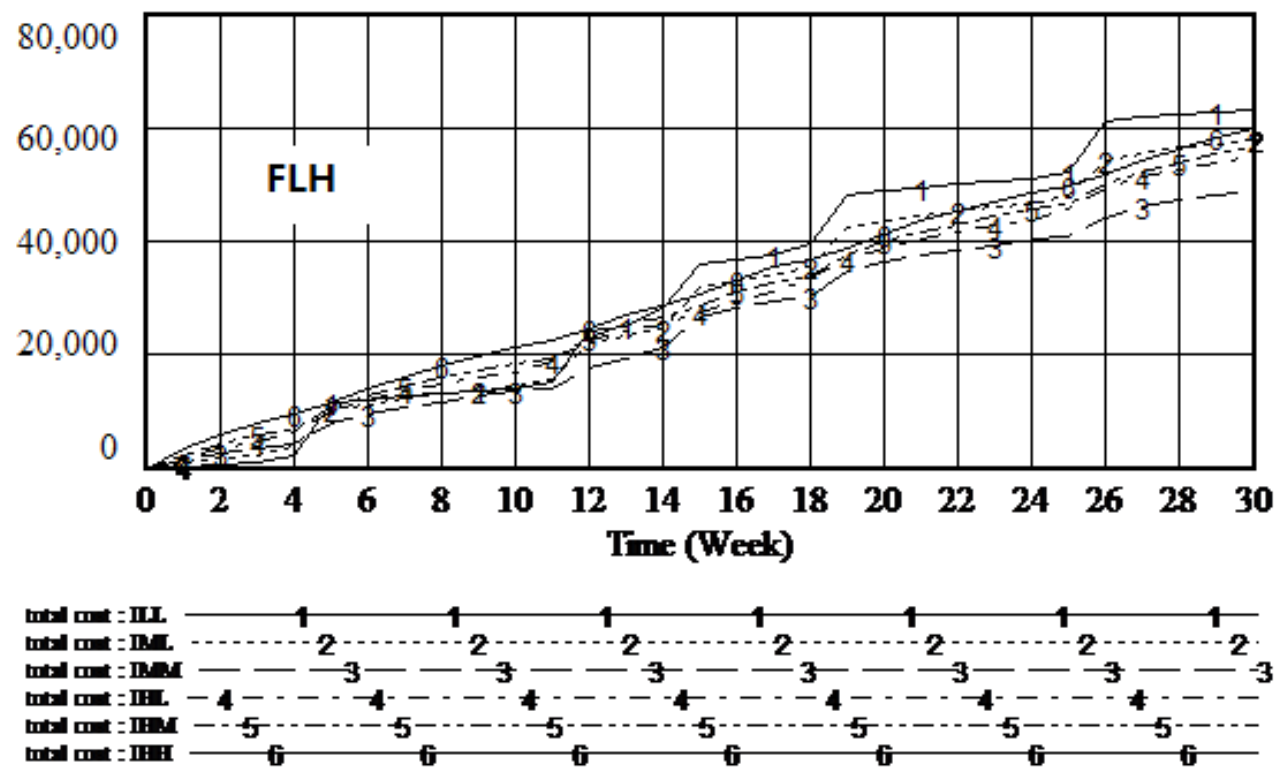

Figure 10: Total cost of different inventory policies with transshipment when disaster frequency is low \& high 
INDEPENDENT JOURNAL OF MANAGEMENT \& PRODUCTION (IJM\&P)

http://www.ijmp.jor.br

v. 4, n. 2, July - September 2013.

ISSN: 2236-269X

DOI: 10.14807/ijmp.v4i2.105

In Figure 10, we can see that under condition FLH, with disaster frequency of $i$ being low while the disaster frequency of $\mathrm{j}$ is high, the total cost of inventory policy ILL is the highest and the total cost of inventory policy IMM is the lowest, see line 1 and line 3 in Figure10. Under this condition, keeping a low inventory is not the best for both sides. We also notice that the differences among total costs of different inventory policies are not as obvious as that of the former two conditions, FLL and FLM.
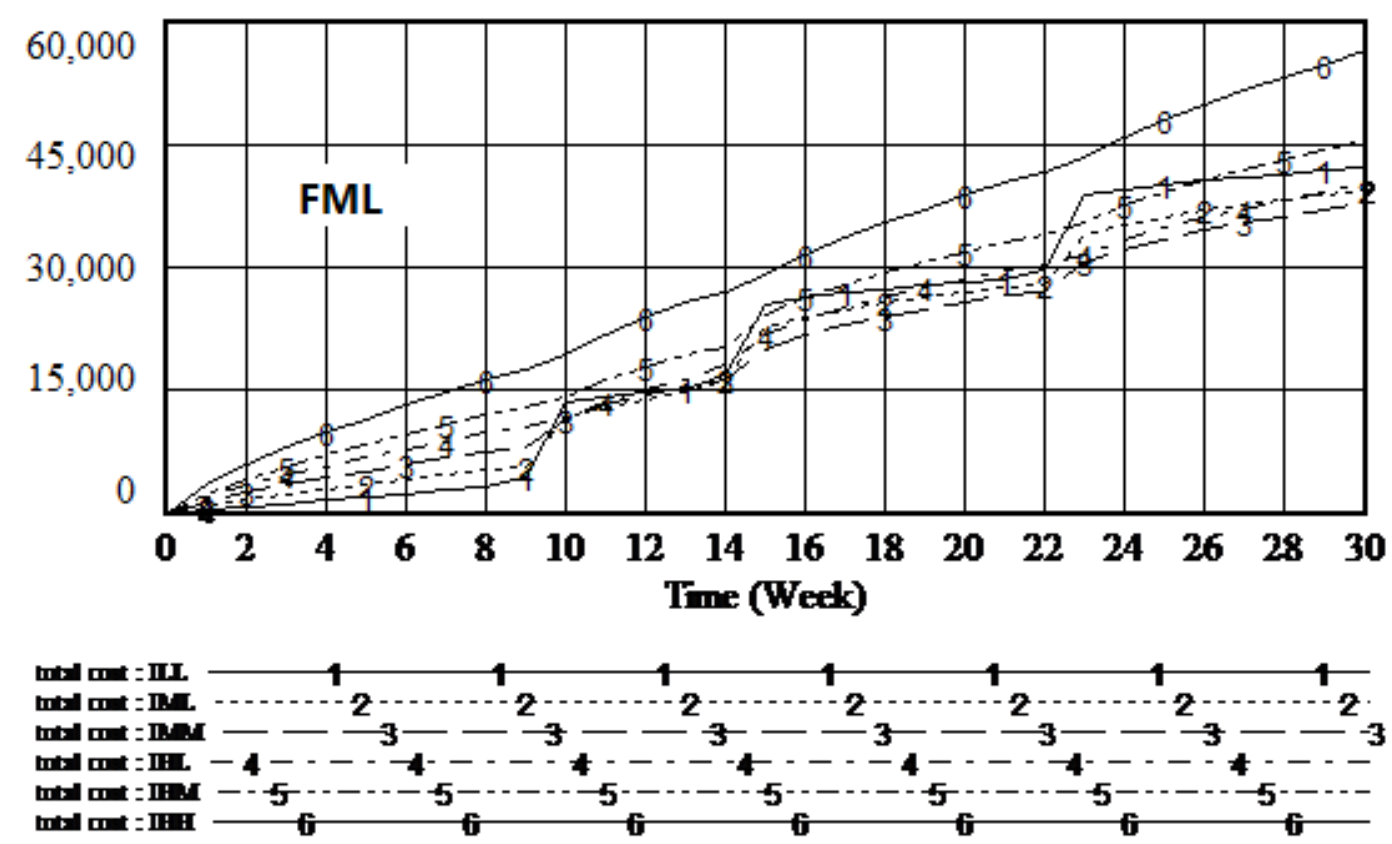

Figure 11: Total cost of different inventory policies with transshipment when disaster frequency is medium \& low
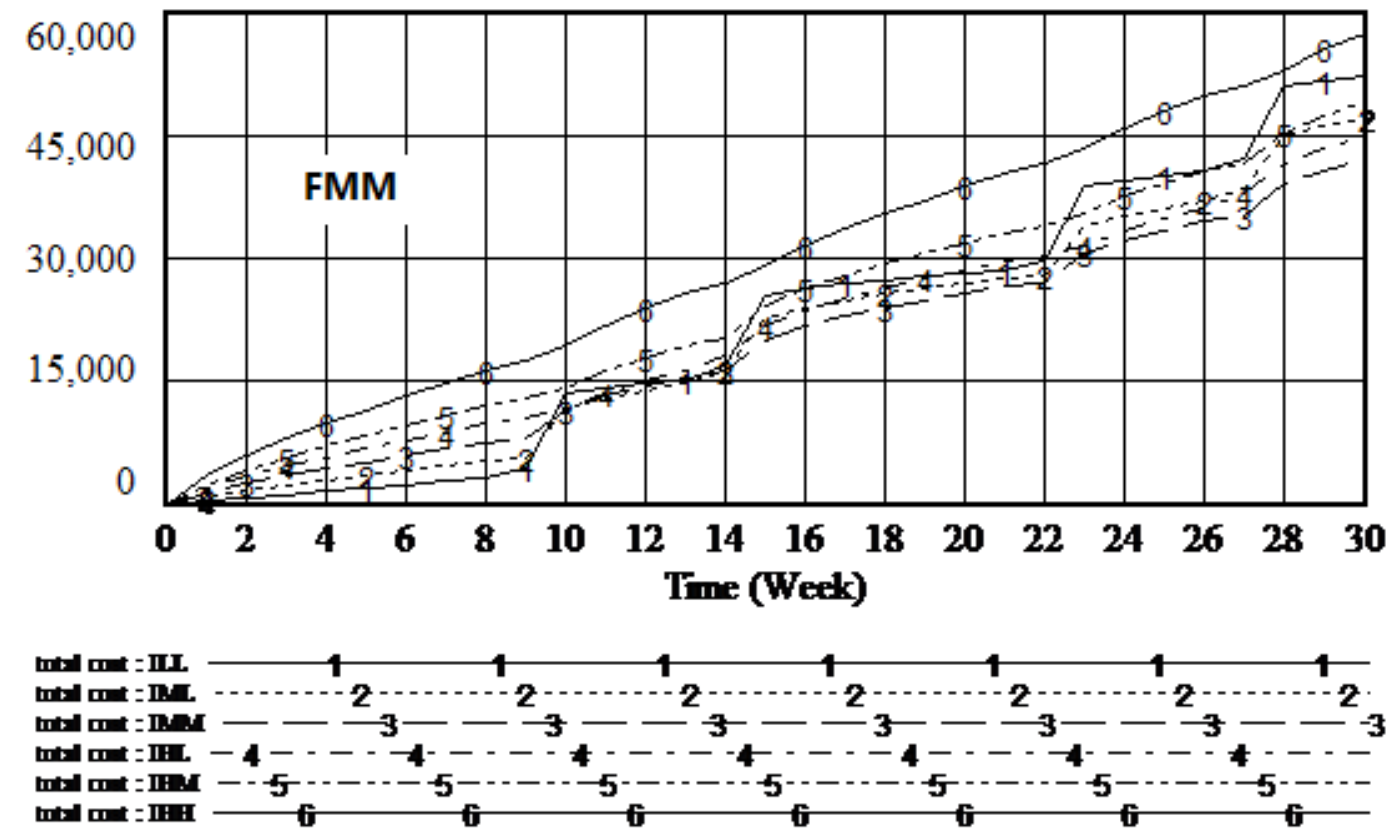
INDEPENDENT JOURNAL OF MANAGEMENT \& PRODUCTION (IJM\&P)

http://www.ijmp.jor.br

v. 4, n. 2, July - September 2013.

ISSN: 2236-269X

DOI: 10.14807/ijmp.v4i2.105

Figure 12: Total cost of different inventory policies with transshipment when disaster frequency is medium \& medium

In Figure 11 and Figure 12, we can see that under condition FML and FMM, where the disaster frequency of $i$ is medium and the disaster frequency of $j$ is low or medium, the total cost of inventory policy $\mathrm{IHH}$ is the highest and the total cost of inventory policy IMM is the lowest, see line 6 and line 3 in both Figure 11 and Figure 12, just the same as the first two conditions, FLL and FLM. But the total cost of ILL is much higher.

Just like the conclusion of Figure 10, when at least one of the disaster frequencies is high, the total cost of inventory policy ILL is the highest; see line 1 in the following four figures, Figure 13 to Figure 16.
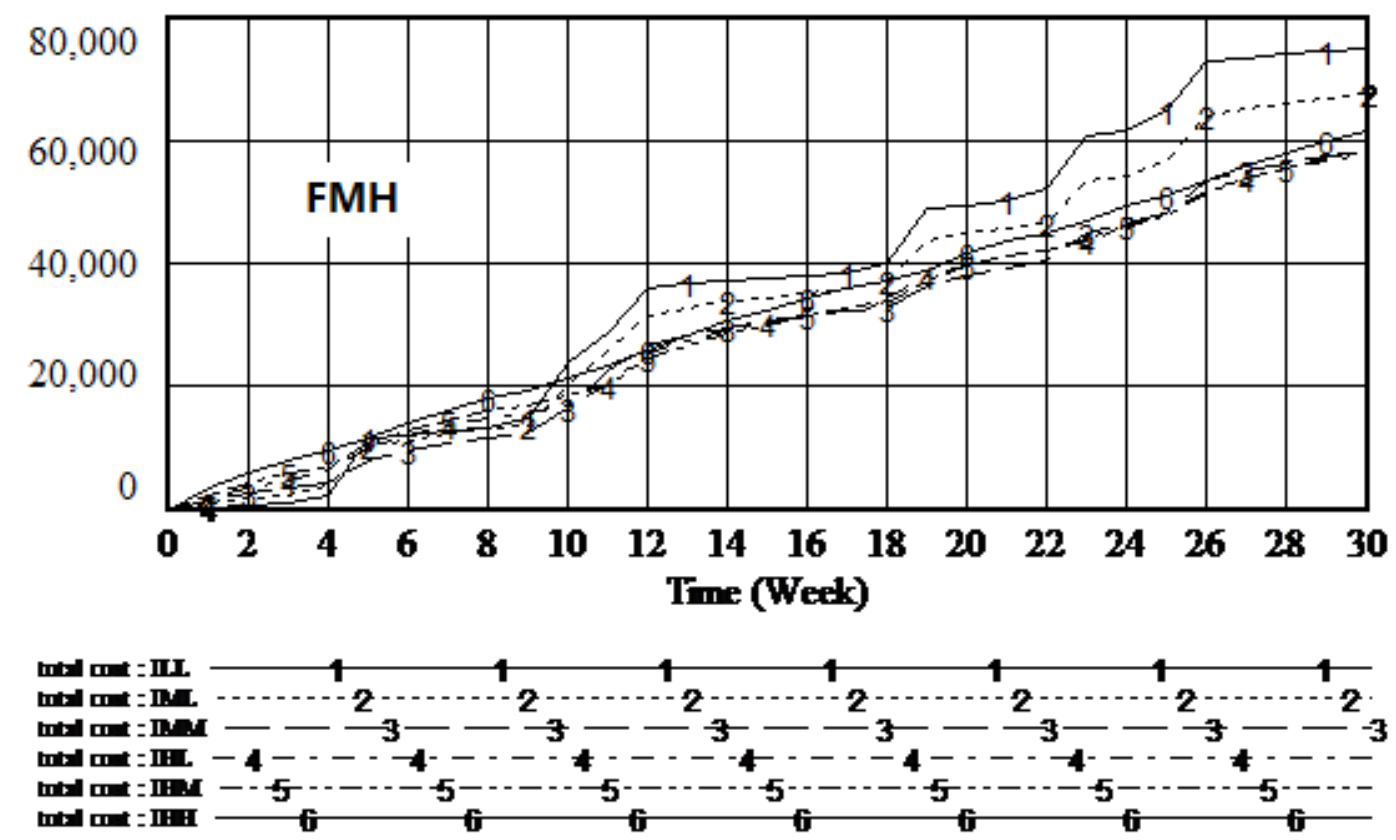

Figure 13: Total cost of different inventory policies with transshipment when disaster frequency is medium \& high

In Figure 13, under condition $\mathrm{FMH}$, where the disaster frequency of $\mathrm{i}$ is medium and the disaster frequency of $\mathrm{j}$ is rather high, the best inventory policies are IMM, IHL, IHM and IHH. 
ISSN: 2236-269X

DOI: 10.14807/ijmp.v4i2.105
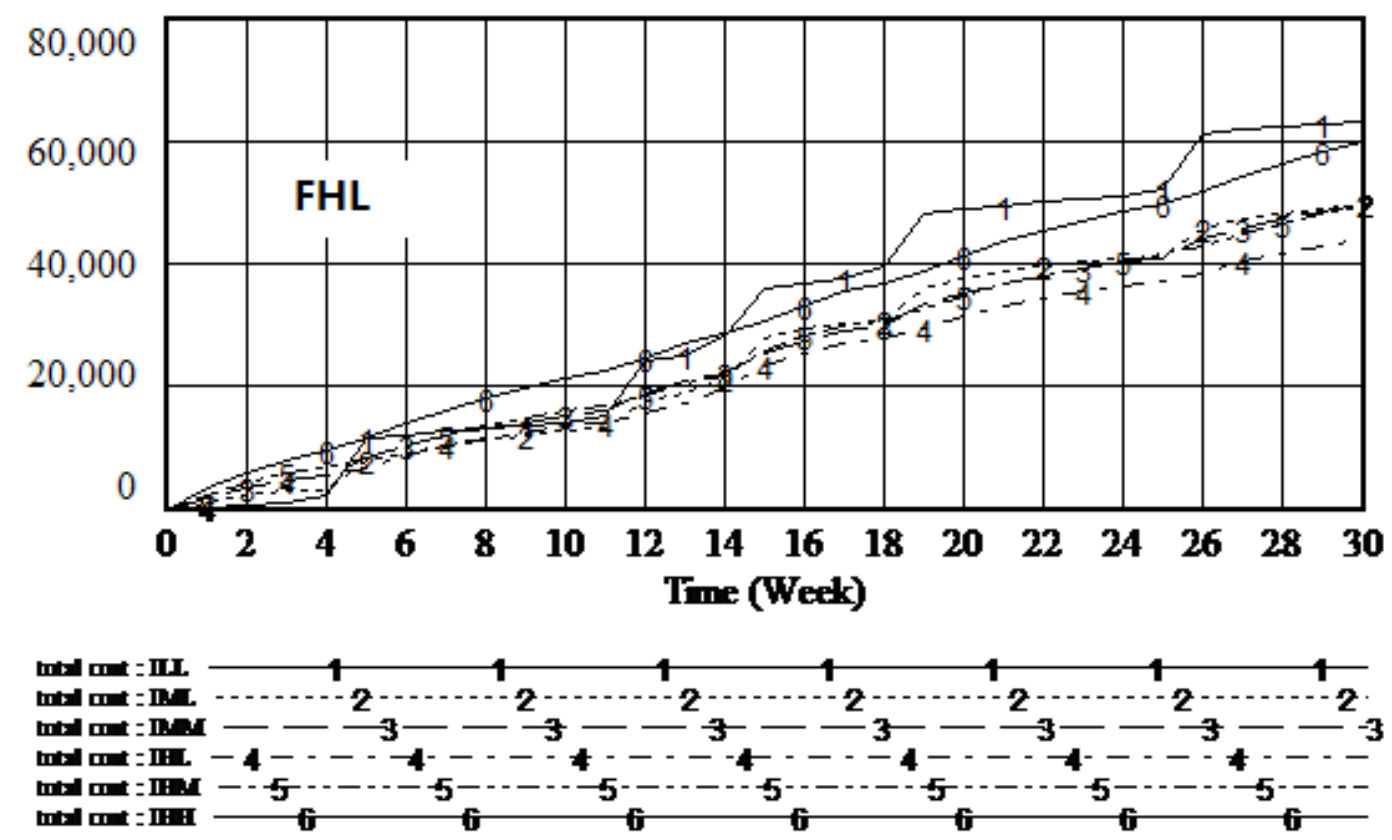

Figure 14: Total cost of different inventory policies with transshipment when disaster frequency is high \& low

In Figure 14, under condition FHL, where the disaster frequency of $\mathrm{i}$ is high and the disaster frequency of $\mathrm{j}$ is rather low, the best inventory policies are IML, IMM, $\mathrm{IHL}$, and IHM.
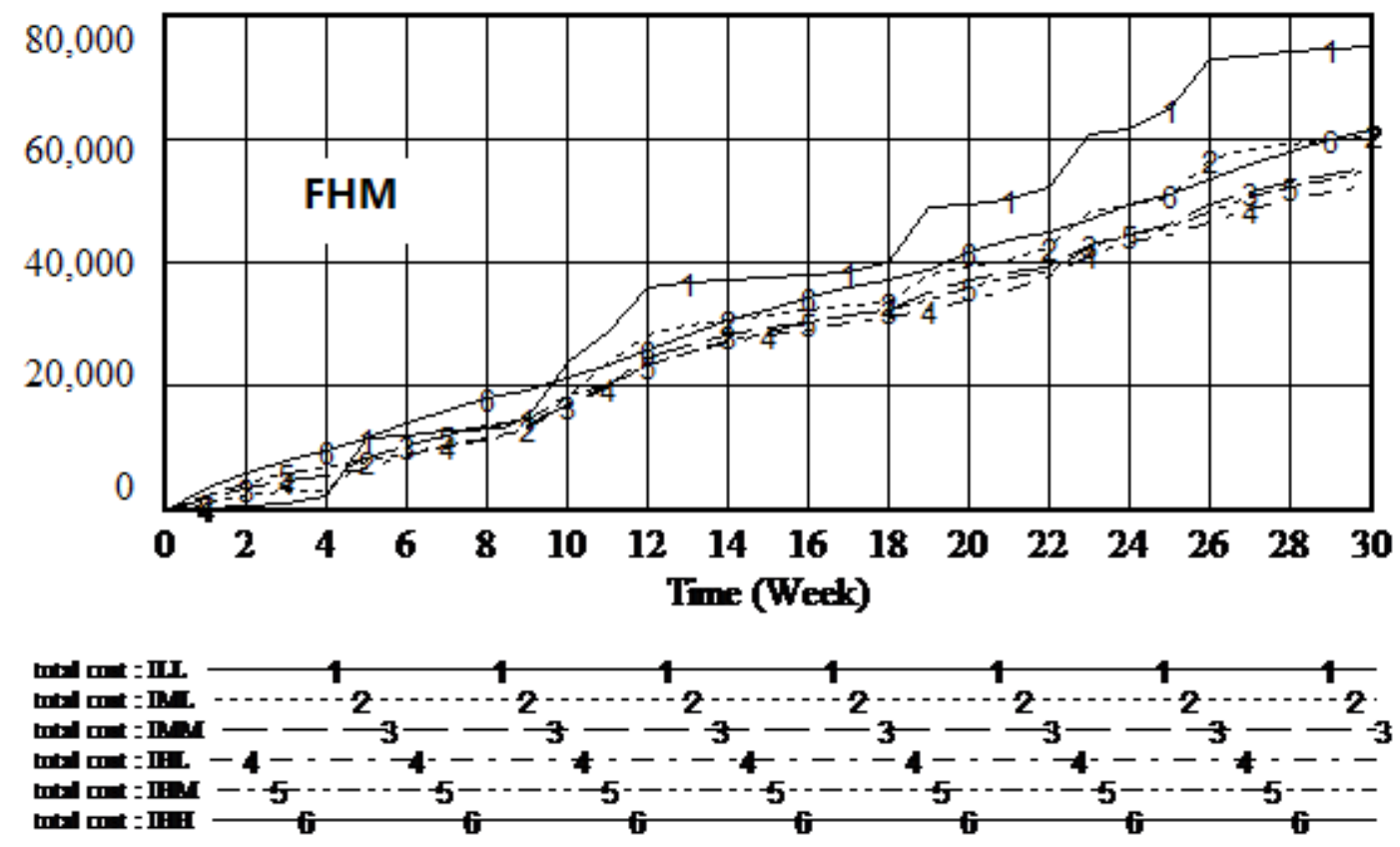

Figure 15: Total cost of different inventory policies with transshipment when disaster frequency is high \& medium 
INDEPENDENT JOURNAL OF MANAGEMENT \& PRODUCTION (IJM\&P)

http://www.ijmp.jor.br

v. 4, n. 2, July - September 2013.

ISSN: 2236-269X

DOI: 10.14807/ijmp.v4i2.105

In Figure 15, under condition FHM, where the disaster frequency of $\mathrm{i}$ is high and the disaster frequency of $\mathrm{j}$ is medium, the best inventory policies are IMM, IHL, and IHM.
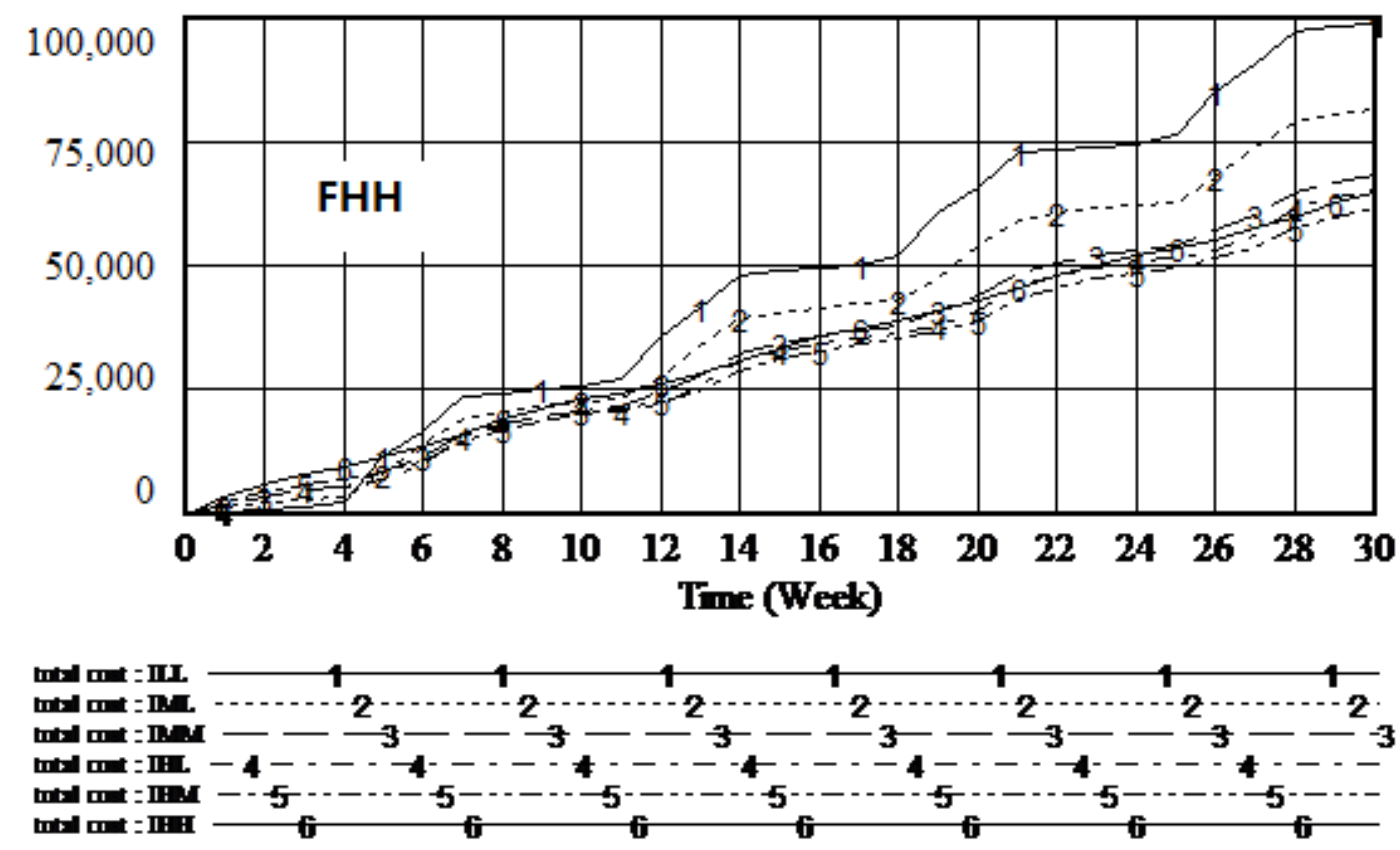

Figure 16: Total cost of different inventory policies with transshipment when disaster frequency is high \& high

In Figure 16, under condition $\mathrm{FHH}$, where the disaster frequencies of $\mathrm{i}$ and $\mathrm{j}$ are all high, the best inventory policies are IMM, IHL, IHM and IHH. If only the total are considered, from the conclusions based on Figure 8 to Figure 16, the best inventory policies under different disaster frequencies are given in table 3.

Table 3: Best inventory policy under different disaster frequencies

\begin{tabular}{|l|l|}
\hline Character of Disaster & Best inventory policy or policies \\
\hline FLL & ILL, IML, IMM \\
\hline FLM & IMM \\
\hline FLH & IMM \\
\hline FML & IMM \\
\hline FMM & IMM \\
\hline FMH & IMM, IHL, IHM and IHH \\
\hline FHL & IML, IMM, IHL, and IHM \\
\hline FHM & IMM, IHL, and IHM \\
\hline FHH & IMM, IHL, IHM and IHH \\
\hline
\end{tabular}


INDEPENDENT JOURNAL OF MANAGEMENT \& PRODUCTION (IJM\&P)

http://www.ijmp.jor.br

V. 4, n. 2, July - September 2013.

ISSN: 2236-269X

DOI: 10.14807/ijmp.v4i2.105

From Table 3, for all disaster frequency conditions, IMM and IHL are better than other inventory policies. Furthermore, we can conclude that if the probability or frequency of disaster is uncertain, inventory IMM is the optimized policy. That is, both of the warehouses only need to keep medium inventory no matter the disaster frequencies are low, medium or high.

\subsection{Efficiency of transshipment}

In order to compare the efficiency of transshipment, we will discuss the simplest conditions first, both probabilities of disaster and desired inventories of $i$ and $\mathrm{j}$ are the same, that is:

$p_{i}=p_{j}$, Inventory $\mathrm{i}=$ Inventory $\mathrm{j}$

Under this condition, the simulation results of inventory $i$ equals to that of inventory $\mathrm{j}$. therefore, we only need to analyze the results of inventory i. Suppose probabilities of disaster are medium, inventory policies is low and medium. Different costs of inventory $i$ are described as difference lines in Figure 17.

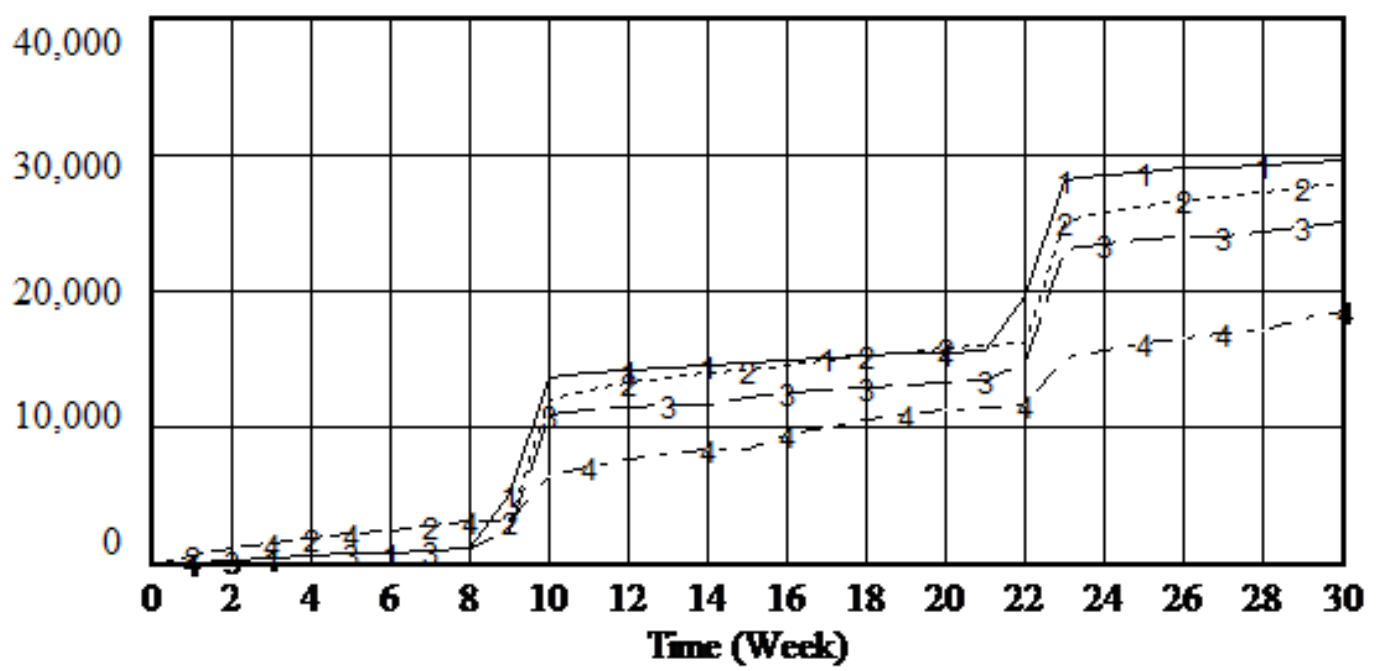

LOW INVENTORY WITHOUT TRANSSHIPMENT $\longrightarrow+1,1$ MFDIUM INVENTORY WITHOUT TRANSSHIPMFNT $2 \cdots \cdots$ LOW INVENTORY WITH TRANSSHIPMFNT $-3-3-3-3-$

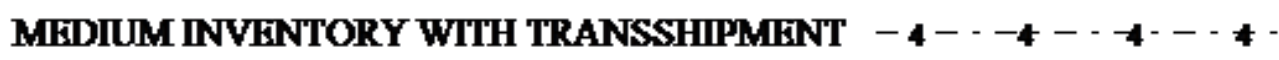

Figure 17: Total cost with and without transshipment

Based on Figure 17, we will do two groups of comparing:

Comparing different cost without transshipment, line1 and line 2 
Desired inventory of line 1 is 100 , line 2 is 200 . Costs of these two policies are all high because emergency purchase is necessary for both of them. Only when the inventory is high, can the total cost be reduced (shown line3 in Figure 7). When there is no transshipment between warehouses, all the warehouses must hold high inventories to satisfy the relief demand and avoid emergency purchase.

Comparing different cost with transshipment: line 3 and line 4

When the desired inventory is 100 (line 3 in Figure 14) cost is high because emergency purchase is necessary for this policy, however when the desired inventory is 200 (line 4 in Figure 17), cost is low because the unfulfilled demand can be fulfilled by transshipment from inventory $\mathrm{j}$. In other words, emergency purchasing disappeared under this condition, shown in Figure 18.
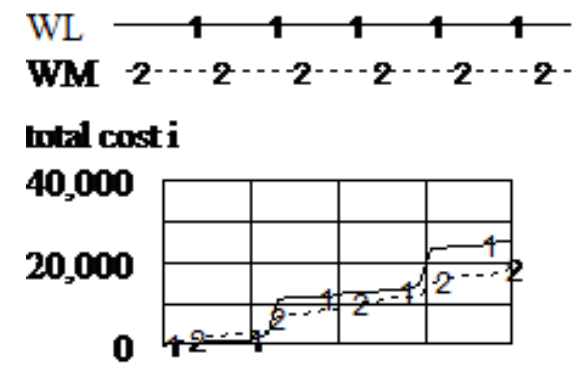

\section{Total disposal cost $i$}

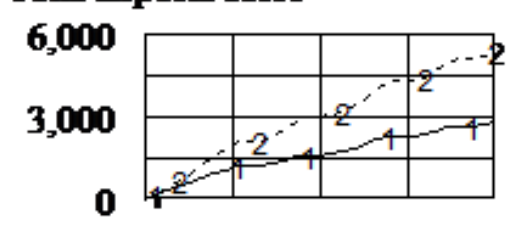

Total emergency purchase cost $i$

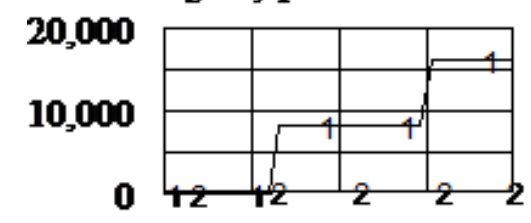

Total pre-puchase cost $\vec{r}$

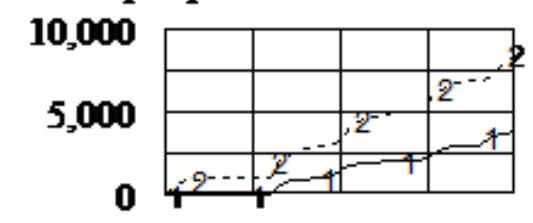

\section{Total transsstipment costi}

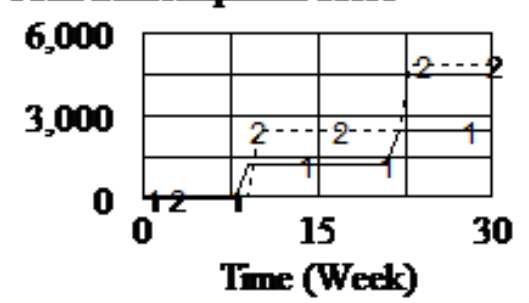

Figure 18: Cost comparing for different inventory policy with transshipment 
INDEPENDENT JOURNAL OF MANAGEMENT \& PRODUCTION (IJM\&P)

http://www.ijmp.jor.br

v. 4, n. 2, July - September 2013.

ISSN: 2236-269X

DOI: 10.14807/ijmp.v4i2.105

We cannot always reduce the total cost by reducing our desired inventory even when we can get transshipment from other warehouses. To take advantage of transshipment certain conditions must be met illustrated in Figure 19.
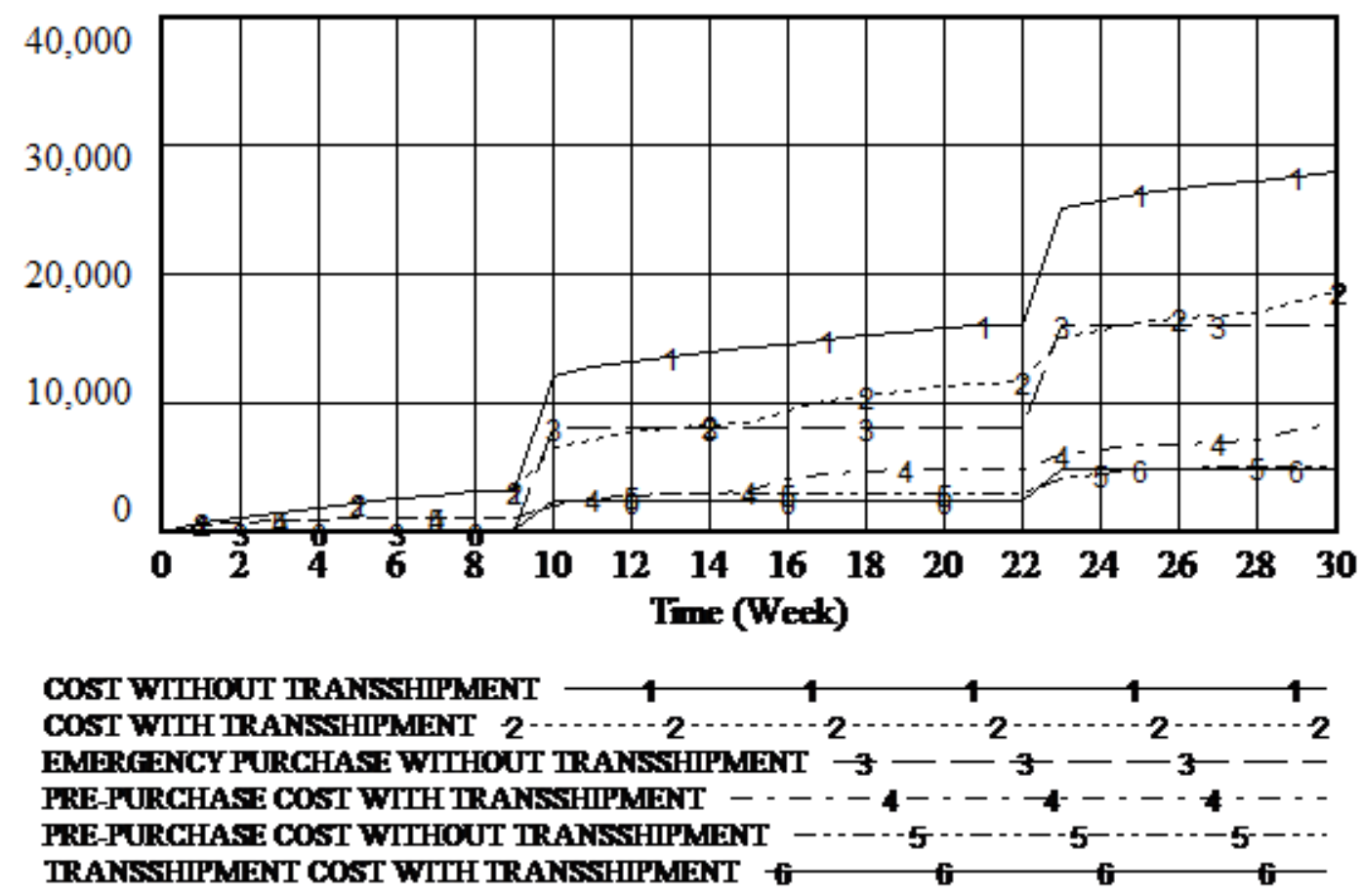

Figure 19: Cost structure with and without transshipment

In Figure 19 we notice that when inventory policies are the same (medium), the pre-purchase cost with transshipment (line 4) is higher than that of without transshipment (line 5). The reason is that, in order to fulfill the transshipment demand of inventory j, inventory i must purchase more after relief to j. As a result, transshipment is available only when the unit emergency purchase cost of $\mathrm{i}$ is higher than the unit pre-purchase cost of $i$ and unit transshipment cost of $j$.

\section{CONCLUSION}

This research gives a disaster relief system based on transshipment which proved to be efficient via our simulation example. In our simulation, we only discussed a transshipment system with two warehouses whose unit costs are the same. We assumed that the probable frequency of a disaster is unknown but the maximum demand is known as a constant if the disaster happened. Of course the decision makers can describe the demand and character of different warehouses in detail if they have enough data. That is, our system given in Figure 4 and Figure 6 can be easily modified by adjusting the parameters and equations. 
The results of our simulation on transshipment for all disaster frequency conditions showed that if the probability or frequency of disaster is uncertain, inventory IMM is the optimized policy. That is, both of the warehouses only need to keep medium inventory no matter whether the disaster frequencies are low, medium or high. This is important for warehouse managers to understand in order to minimize costs and be aware of the ability to provide relief when needed. But, if inventory levels are too low, then emergency purchasing is high resulting in increased cost and possible delayed relief to those in need.

Without transshipment, inventory levels must be kept at a higher level increasing costs and waste. Also, emergency purchasing in a necessary evil which drives up costs even more. Management of a disaster system without transshipment would require a more inventory, planning, and supervisory control.

Transshipment is outperformed when the pre-purchase costs are factored in due to higher emergency purchase costs. Otherwise transshipment out performs systems without transshipment.

In all cases, the key to reducing costs and providing the best care for disaster victims is the information technology and knowledge discovery subsystem. The accuracy of information allows for the output of reliable relief plans in order to get relief supplies to victims by transshipment or purchasing where purchasing is native (local/regional) or global. If our relief plan is to purchase, then managers can go to purchase system, or else to the inventory system to judge if the inventory in the local warehouse is enough or if transshipments are necessary, and how to choose the suppliers. The transshipment requirements can be met only with advanced information systems/technology, which allow managers/relief supervisors to see what other managers/relief supervisors have in stock and facilitate rapid shipping between warehouses. Knowledge discovery is key to the process.

Future research will examine more complex systems for disaster relief, allowing for more variability in the system. This research is a first step in determining how best to help improve humanitarian efforts to save lives and help relief organizations and benevolent organizations provide relief when needed. 
INDEPENDENT JOURNAL OF MANAGEMENT \& PRODUCTION (IJM\&P) http://www.ijmp.jor.br

v. 4, n. 2, July - September 2013.

ISSN: 2236-269X

DOI: 10.14807/ijmp.v4i2.105

\section{REFERENCES}

BALCIK, B.; BEAMON, B.; KREJCI, C.; MURAMATSU, K.; AND RAMIREZ, M. (2010). Coordination in humanitarian relief chains: Practices, challenges and opportunities. International Journal of Production Economics, v. 126, n. 1, p. 2234.

BONNEY, M.; JABER, M. Y. (2011). Environmentally responsible inventory models: Non-classical models for a non-classical era. International Journal of Production Economics, v. 133, n. 1, p. 43-53.

EGAN, M. J. (2010). Private goods and services contracts: Increased emergency response capacity or increased vulnerability? International Journal of Production Economics, v. 126, n. 1, p. 46-5

LODREE, E. J.; TASKIN, S. (2009). Supply chain planning for hurricane response with wind speed information updates. Computers \& Operations Research, v.36, n. 1, p. $2-15$

OLORUNTOBA, R. (2010). An analysis of the Cyclone Larry emergency relief chain: Some key success factors. International Journal of Production Economics, v. 126 , n. 1, p. 85-101.

OLSSON, F. (2010). An inventory model with unidirectional lateral transshipments.

European Journal of Operational Research, v. 200, n. 3, p. 725-732.

PATERSON, C.; KIESMÜLLER, G.; TEUNTER, R.; GLAZEBROOK, K. (2010). Inventory models with lateral transshipments: A review. European Journal of Operational Research, v. 210, n. 2, p. 125-136.

REYES, P. M. (2005). Logistics networks: A game theory application for solving the transshipment problem. Applied Mathematics and Computation, v. 168, n. 2, p. 1419-1431.

TANG, S-L.; AND YAN, H. (2012). Pre-distribution vs. post-distribution for crossdocking with transshipments. Omega, v. 38, n. 3-4, p. 192-202.

WHYBARK, D. C. (2007). Issues in managing disaster relief inventories.

International Journal of Production Economics, v. 108, n. 1-2, p. 228-235.

YANG, T., WEN, Y-F, AND WANG, F-F. (2011). Evaluation of robustness of supply chain information-sharing strategies using a hybrid Taguchi and multiple criteria decision-making method. International Journal of Production Economics, v. 134, n. 2, p. 458-466. 